\title{
Nanoviricides Platform Technology based NV-387 polymer Protects \\ Remdesivir from Plasma-Mediated Catabolism in vitro: Importance of its increased lifetime for in vivo action
}

Ashok Chakraborty ${ }^{1 *}$, Ph.D.; Anil Diwan ${ }^{2}$, Ph.D.; Vinod Arora ${ }^{1}$, Ph.D., Yogesh Thakur ${ }^{1}$, MS., Preetam Holkar ${ }^{1}$, MS., and Vijetha Chinige ${ }^{1}$, MS.

\author{
${ }^{1}$ Allexcel, Inc., West Haven, CT, USA \\ ${ }^{2}$ Nanoviricides, Inc., Shelton, CT, USA
}

KeyWords: Remdesivir, COVID-19, SARS-CoV-2, Therapy, Vaccine, Antiviral, NV-CoV-2 (387-Polymer), Nanoviricides

\author{
Abbreviations: \\ CoV: Coronavirus; \\ MERS: Middle East Respiratory \\ HCoV: Human Coronavirus \\ Syndrome; \\ FDA: Food and Drug Administration \\ RBD: Receptor Binding Domain \\ hAPN: human Aminopeptidase N; \\ hACE2: human Angiotensin \\ HAT: Human Airway Trypsin-like Converting enzyme 2 \\ protease; \\ RNA: Ribonucleic Acid; \\ SARS: Severe Acute Respiratory \\ Syndrome; \\ hDPP4: human Dipeptidyl Peptidase 4; \\ IBV: Infectious Bronchitis Virus; \\ TMPRSSII: Transmembrane Protease
}

\section{Corresponding Author:}

- Ashok Chakraborty, Ph.D. Email: ashok.chakraborty@allexcel.com 


\begin{abstract}
:
As of today seven coronaviruses were identified to infect humans, out of which only 4 of them belongs to beta family of coronavirus, like HCoV-HKU1, SARS-CoV2, MERS-CoV and SARS-CoV. SARS family of viruses were known to cause severe respiratory disease in humans. SARS-CoV-2 infection causes pandemic COVID-19 disease with high morbidity and mortality. Remdesivir (RDV) is the only antiviral drug so far approved for Covid-19 therapy by FDA. However it's efficacy is limited in vivo due to it's low stability in presence of Plasma.

Here we show the stability of RDV encapsulated with our platform technology based polymer NV-387 (NV-CoV-2-R), in presence of Plasma in vitro in comparison to naked RDV when incubated in plasma. The potential use of this polymer in vivo will be discussed, here.
\end{abstract}




\section{Introduction:}

A new threat to human life, in recent days, is the outbreak of SARS-CoV-2 human corona virus in China, at Wuhan City in late December 2019 [1] [Andersen et. al. 2020]. SARS-COV-2 is a beta family of human coronavirus and stands for "Severe Acute Respiratory Syndrome Coronavirus 2" that causes the severe lower tract infection called COVID-19 [For rev. 2-4] [Singhal 2020; Chakraborty et. al. 2020, 2020a]. As of Sept 30, 2021, the world-wide SARS-CoV-2 infected cases are more than 219M and death number is about 4.55M [5] [Covid.cdc.gov/covid-data-tracker/; Updated: Sept 12, 2021]. In USA, there have been over 44.5 million confirmed cases with 715K deaths (approx.). [6] [WHO Coronavirus Disease (COVID-19) Dashboard. Data last updated: 2021/10/10. https://covid19.who.int/].

The infection capabilities of SARS-CoV-2 are believed to be primarily due to its increased affinity for the angiotensin-converting enzyme 2 (ACE2) receptor on the body's cell surface [1, 2] [Andersen et. al. 2020; Singhal 2020]. We have recently written an article on referring the zoonosis, susceptibility and different strategies to develop therapeutics [3] [Chakraborty et. al. 2020].

COVID-19 was declared as a global pandemic on 11 March 2020, by the WHO, however, the evidence for therapies against this virus is as yet inadequate. Various medical teams are prescribing drugs for this collection of ailments based on some mechanistic data but with limited clinical findings in support of their activity. The clinical importance of pre-clinically validated regimens relies on the available pharmacokinetic (PK) data for the particular drug [1, 3] [Andersen et. al. 2020; Chakraborty et. al. 2020].

SARS-CoV-2 virus enters a host cells by binding to and fusing with cell 
membrane receptor, ACE-2, followed by membrane fusion. Once inside, the virus uses the host cell's machinery to replicate, using the virus's RNA dependent RNA polymerase (RdRp) for making genome and transcript copies. Among the different strains of the corona virus, this non-structural protein is unique in structure, and thus making it a potentially useful drug target. Sofosbuvir, a synthetic analogue of nucleosides and nucleotides which inhibits RdRp has led to a successful treatment for hepatitis C infection [7] [Xie et. al. 2016]. Based on these facts, remdesivir was approved by FDA in various clinical trials for the treatment of COVID-19 infected people [8] [COVID-19 Treatment Guidelines. 2020. https://www.covid19treatmentguidelines.nih.gov/antiviral-therapy/remdesivir/].

Remdesivir, formerly known as GS-5734, is a nucleotide analogue that is claimed to have been originally developed as a treatment against Ebola [3]. This drug can also inhibit corona virus replication by inhibiting RNA polymerases (RdRp4). This compound has shown broad antiviral activity in vitro against Middle East respiratory syndrome coronavirus (MERS-CoV), severe acute respiratory syndrome coronavirus 1 (SARS-CoV-1), and SARS-CoV-2 [9-11] [Gordon et. al. 2020; Sheahan et. al. 2017; Wang et. al. 2020].

In animal studies, remdesivir has been found effective in protecting rhesus monkeys from MERS-CoV infection, when given prior to infection [12] de Wit E, et. al. 2020]. It also protected African green monkeys from Nipah virus, a cause of fatal encephalitis; and also rhesus monkeys from Ebola virus [13, 14] [Lo MK, et. al. 2019; Warren TK, et. al. 2016]. A randomized, well marked, controlled animal study with 12 rhesus monkeys infected with SARS-CoV-2 reported that an attenuation of respiratory symptoms and reduction in lung damage with remdesivir administered 12 hours after virus infection [15] [Williamson. et. al. 2020]. 
However, there are a lot of limitation of using remdesivir in vivo against COVID-19. (i) Efficacy of remdesivir in vitro does not match with the clinical outcomes in humans. (ii) Further, remdesivir has some side effects. In the Ebola trial, the side effects of remdesivir (RDV) were possible liver damage [16] [Remdesivir (RDV). 2020. https://www.rxlist.com/consumer_remdesivir_rdv/drugs-condition.htm]; and also affects kidney and mitochondria $[\mathbf{1 7}, \mathbf{1 8}]$ [Adamsick ML, et. al. 2020; Saleh J, et. al. 2020].

Besides, remdesivir is not stable in presence of Plasma. Metabolism of RDV decreases the effective concentration of the drug, in vivo, and the time of exposure with the drug that may be needed to eliminate the virus.

We searched for the methodologies to protect remdesivir from plasma-mediated metabolism. NanoViricides, Inc. (Shelton, CT, USA) is probably the only company that has developed a PEG-based polymer comprised of a polyethylene glycol (PEG1000) and C16-alkyl pendants in the monomer unit. PEG forms the hydrophilic shell; while the alkyl chains float together to make a flexible core, like an immobilized oil droplet. This polymer can (a) directly attack the virus and disable them from infecting human cells, and simultaneously, and (b) block the reproduction of the virus that has already gone inside a cell (Fig. 1). Together, this double-whammy would result in a cure [3] [Chakraborty and Diwan, 2020].

In this communication our objective is to determine the efficacy of the polymer whether can protect RDV from plasma-mediated catabolism. Time dependent RDV level were measured by LC-MS analysis after incubation of the naked RDV vs polymer encapsulated RDV with rat plasma in vitro. RDV-metabolite, GS-441524 was 
also measured to justify the RDV breakdown. For comparison we used commercially available Gilead Remdesivir, and as a negative control we used vehicle (DMSO:MeOH, 1:9). Here we report our results.

\section{Materials and Methods:}

\section{1: Test Articles (Table-1.1):}

\begin{tabular}{|c|l|c|c|}
\hline SL\# & \multicolumn{1}{|c|}{ Test Article } & Test Article description & $\begin{array}{c}\text { Concentration (mg/mL) } \\
\text { NV-CoV-2/ RDV }\end{array}$ \\
\hline 1 & NV-1067-387-Medium & NV-CoV-2 (Polymer) & $16 / 0$ \\
\hline 2 & NV-1067-387-High & NV-CoV-2 (Polymer) & $32 / 0$ \\
\hline 3 & NV-1067-387-R-Low & NV-CoV-2+Remdesivir & $8 / 0.8$ \\
\hline 4 & NV-1067-387-R-Medium & NV-CoV-2+Remdesivir & $16 / 1.6$ \\
\hline 5 & NV-1067-376 & SBECD+Remdesivir & $0 / 1.0$ \\
\hline 6 & NV1067-377 & Dulbecco's buffer (PBS) & $0 / 0$ \\
\hline
\end{tabular}

\section{2: Sources of Reagents (Table-1.2):}

\begin{tabular}{|c|c|c|c|c|}
\hline $\operatorname{Item}(s)$ & Vendor & Cat\# & Lot\# & Description \\
\hline PBS 1X, pH 7.4 & Life Technologies & & & $\mathrm{pH} 7.2$ \\
\hline Low-binding tubes & Eppendorf & 20431081 & & \\
\hline Na-Acetate Buffer 1M, pH 5.2 & Sigma & S7899 & $\begin{array}{l}\text { SLBS554 } \\
9\end{array}$ & \\
\hline Acetonitrile for precipitation & & & & $100 \%$ \\
\hline Rat- Plasma-Sprague Dawley & $\begin{array}{l}\text { Innovative } \\
\text { Research }\end{array}$ & $\begin{array}{l}\text { IGRT-Na- } \\
\text { EDTA } 22443\end{array}$ & & $\begin{array}{l}\text { Anticoagulant } \\
\text {-Na-EDTA }\end{array}$ \\
\hline Remdesivir (RDV) & $\begin{array}{l}\text { Medkoo } \\
\text { Biosciences, Inc. }\end{array}$ & 329511 & $\begin{array}{l}\text { E20004S0 } \\
1\end{array}$ & \\
\hline GS-441524 & $\begin{array}{l}\text { Medkoo } \\
\text { Biosciences,. }\end{array}$ & 555299 & $\begin{array}{l}\text { C20R07B } \\
09\end{array}$ & \\
\hline ISTD $\left({ }^{13} \mathrm{C}_{6}\right.$-isotope) for RDV & AlsaCHIM & 8845 & $\begin{array}{l}\text { MJ-ALS- } \\
\text { 20-037-P1 }\end{array}$ & \\
\hline ISTD $\left({ }^{13} \mathrm{C}_{5}\right.$-isotope $)$ for $\mathrm{GS}$ & AlsaCHIM & 8855 & $\begin{array}{l}\text { MJ-ALS- } \\
\text { 20-050-P1 }\end{array}$ & \\
\hline Isopropanol & Sigma-Adrich & & & $75 \%$ \\
\hline
\end{tabular}

\section{3: Standard Curve Preparation of Remdesivir and GS-441524 were} determined by using LC-MS, using different concentration of the standards solution in 
$\mathrm{DMSO}+\mathrm{MeOH}(1: 9)$ ranging from 0-5 ng/uL final concentrations. Plasma and/or PBS were used in the reaction mixture, as when needed. As an internal standard (ISTD) ${ }^{13} \mathrm{C}_{6}$ $-\mathrm{RDV}$ and ${ }^{13} \mathrm{C}_{5}$-GS441524, $2.5 \mathrm{ng} / \mathrm{uL}$ each, were used, respectively for RDV and GS assay, and or in mixture. The Final concentration of the internal standards in the reaction mixture becomes $0.125 \mathrm{ng} / \mathrm{uL}$. Extraction of RDV and it's metabolite GS441524, for LC-MS assay were done by using Acetonitrile.

Concentrations of RDV and GS-441524 vs. their ratio with the internal standards, ISTDs $\left({ }^{13} \mathrm{C}_{6}\right.$-RDV, ${ }^{13} \mathrm{C}_{5}$-GS, respectively) were used to generate a standard curve for RDV and GS-441524, respectively, as shown in the Table -2 \& Figure-2.

\section{4: Incubation of test materials with rat plasma (RPL) in vitro, and isolation of the RDV/GS-441524 by Acetonitrile.}

Ten microliter of the test materials $(20 \mathrm{ng} / \mathrm{uL})$ were incubated with $30 \mathrm{uL}$ rat plasma for different time points (as indicated in the Figs.), and then extracted with Acetonitrile $(100 \mathrm{uL})$. The mixture is centrifuged for $10 \mathrm{mins}$ at $10,000 \mathrm{xg}$ to separate the supernatants from the precipitates. The supernatants containing either RDV and/or its metabolites, GS-441524 were determined by LC-MS chromatography (as described below).

1.5: Detection of RDV and GS-441524 by LC-MS spectroscopy: Analysis was performed using the LC and MS analysis conditions shown in Table-1.3, and the multiple reaction monitoring (MRM) data acquisition parameters shown in Table-1.4. Shim-Pack Sceptor ${ }^{\mathrm{TM}}$ C18-120 (50 $\mathrm{mm} \times 22.1 \mathrm{~mm}$ I.D., $\left.1.9 \mathrm{uM}\right)$ was used as the analytical column. 
Table-1.3: Chromatographic Conditions:

\begin{tabular}{|c|c|}
\hline \multicolumn{2}{|r|}{ LC Analysis Conditions } \\
\hline HPLC Method: & RDVmetIS_LC_NoSlit-0.4mL-ExtRinse_202010231219.1cm \\
\hline Column: & $\begin{array}{l}\text { Shimadzu, Shim Pack, Sceptor, C18-120, 2.1x50 mm, } 1.9 \text { um, } \\
\text { Cat\#227-31120-01 }\end{array}$ \\
\hline Pre-Column: & $\begin{array}{l}\text { Guard Column, Shimadzu, Shim-pack, C18-120 EXP (G), } 1.9 \text { um, } 2.1 \mathrm{x} \\
5 \mathrm{~mm} \text {, or Restek prefilter: Ultrafield UHPLC, o.2 um frit, Catalog\# } \\
25810 \text {. }\end{array}$ \\
\hline Mobile Phase: & $\begin{array}{l}\text { A: Water containing } 0.05 \% \text { formic acid } \\
\text { B: Acetonitrile containing } 0.05 \% \text { formic acid }\end{array}$ \\
\hline Gradient: & $\begin{array}{l}0-0.3 \min : 5 \% \mathrm{~B}, \\
0.3-0.35 \min : 30 \% \mathrm{~B}, \\
0.35-1.5 \min : 70 \% \mathrm{~B}, \\
1.5-1.8 \min : 90 \% \mathrm{~B}, \\
1.8-2.8 \min : 90 \% \mathrm{~B}, \\
2.8-2.9 \min : 5 \% \mathrm{~B}, \\
2.9-4.5 \text { min: } 5 \% \mathrm{~B}, \\
\text { (A: Solvent } \mathrm{A} ; \mathrm{B}: \text { Solvent } \mathrm{B} \text { ) }\end{array}$ \\
\hline Injection Volume: & $1 \mathrm{uL}$ \\
\hline
\end{tabular}

Table-1.4: MS MRM Transitions observed (for quantitation):

\begin{tabular}{|l|l|c|l|}
\hline \multicolumn{1}{|c|}{ Compounds } & \multicolumn{1}{|c|}{ Ion } & \multicolumn{1}{c|}{$\begin{array}{c}\text { Precursor Ion } \\
\mathbf{( m / z )}\end{array}$} & \multicolumn{1}{c|}{$\begin{array}{c}\text { Product Ion } \\
(\mathbf{m} / \mathbf{z})\end{array}$} \\
\hline \multirow{2}{*}{$\mathrm{RDV}$ (target, drug): } & Quantitation ion & 603.2 & $200.0(@ 41)$ \\
\cline { 2 - 4 } \begin{tabular}{l} 
Quantitation ion \\
\multirow{2}{13}{$\mathrm{C}_{6}$-RDV (Internal } \\
standard for RDV)
\end{tabular} & Quantitation ion & 603.2 & $229.0(@ 21)$ \\
\cline { 2 - 4 } & Quantitation ion & 609.2 & $206.0(@ 25)$ \\
\hline $\begin{array}{l}\text { GS-441524 (target, } \\
\text { metabolite): }\end{array}$ & Quantitation ion & 609.2 & $229.0(@ 26)$ \\
\cline { 2 - 4 } & Quantitation ion & 292.1 & $163.0(@ 25)$ \\
\hline $\begin{array}{l}{ }^{13} \mathrm{C}_{5} \text {-GS-441524 } \\
\text { (Internal standard for } \\
\text { metabolite) }\end{array}$ & Quantitation ion & 297.1 & $136.0(@ 26)$ \\
\cline { 2 - 4 } & Quantitation ion & 297.1 & $148.0(@ 30)$ \\
\hline
\end{tabular}




\section{7: Calculation of RDV and GS-441524 from the chromatogram:}

The ratio of RDV and its isotope, ${ }^{13} \mathrm{C}_{6}$-ISTD (as an internal standard) was

calculated. Similarly, the ratio of GS and its internal standard, ${ }^{13} \mathrm{C}_{5}$-ISTD was also calculated. From that ratio, the amount of RDV and GS were determined using the linear equation derived from their respective standard curve.

The values were normalized using the Dilution factor $(2 \times 20 \times 4=160)$ used for Original Plasma sample.

\section{Results and Discussion:}

1: Standard Curve of RDV and GS-441524 (Table-2, Fig. 2): A representative standard curve for RDV and GS-441524, both were shown in Fig. 2 with $\mathrm{R}^{2}$ value $(>0.99)$. The experiment was repeated 3 times with similar results.

\section{2: Stability of different RDV test materials in presence of Rat Plasma in vitro} were shown in Figs 3-5.

Test materials are:

(i) $\mathrm{RDV}$ in DMSO: $\mathrm{MeOH}(1: 9)$

(ii) RDV-NV387 (RDV encapsulated in NV-387 polymer)

(iii) RDV-in SBECD (NV1104-376A, Gilead)

Other test materials used in these experiments are the different vehicles used as a negative controls, such as, DMSO:MeOH (1:9), NV-387 polymer itself, and PBS buffer.

In brief, NV-387 Polymer can encapsulate Remdesivir efficiently, as we see RDV-387 show RDV peak in LC-MS chromatography, where as only the polymer NV-387 does not show any RDV peak (data not shown). We have also tried to measure RDV and GS-441524 level in the respective vehicles, like DMSO, Polymer itself NV387, and PBS, but the results are below the detection level (data Not shown). 


\section{Comparative analysis of RDV breakdown and GS-441524 production by} the above test materials in presence of Rat Plasma, in vitro. (Table-3, Fig. 6):

NV-387-polymer encapsulation protects RDV in vitro from plasma-mediated catabolism, thus could protect RDV in vivo for longer period of anti viral effect even more than that of Gilead-RDV (Figs. 6).

Nonetheless our Platform technology based NV-387-encapsulated-RDV drug has a dual effect on coronavirus, as it being itself posses an antiviral activity [19, 20], and also by protecting RDV more than that of Gilead-RDV, renders RDV effectiveness against virus. Further, potential mutations in the virus are unlikely to enable it to escape these drug candidates.

Further, we have already scaled up production of key portions to multi-kilogram scales. We are now initiating an animal model study to finalize two to three best candidates for further testing. We intend to perform certain animal model safety studies, in order to further advance the final candidate for limited human clinical (compassionate) use scenario. This is the fastest timeframe that a drug candidate truly directed at the SARS-CoV-2 has been developed by any Company to date (https://www.marketwatch.com/press-release/nanoviricides-develops-highly-effectivebroad-spectrum-drug-candidates-against-coronaviruses-2020-05-12. Nanoviricides Develops Highly Effective Broad-Spectrum Drug Candidates Against Coronaviruses. Published: May 12, 2020 at 7:15 a.m. ET)

\section{Conclusions:}

It is needless to say that in the present days, rapid design \& construction, as well as synthesis and manufacture of anti SARS-CoV-2 has a crying need. Although our approach are very potential for the COVID-19 therapy, but we have been limited to studying effectiveness against available BSL2 level strains of coronaviruses, as they do not cause the severe pathology in humans. No other drug currently available in the 
development for SARS-CoV-2 virus in the USA, be it antibody, small chemical, or otherwise, has been tested against any coronaviruses at present, to the best of our knowledge.

We are in contact with USAMRIID (United States Army Medical Research Institute of Infectious Diseases) and Robert Davey at NIEDL in Boston, for testing against SARS-CoV-2 itself. We have not received back a Materials Transfer Agreement to enable initiating these studies. Meanwhile its report to scientific community as well as to the common people for their attention and assistance in furthering this endeavor, to contribute to the fight against the SARS-CoV-2 pandemic and position to win the fight.

Conflict of Interests: Author, Anil Diwan, was employed by the company Nanoviricides, Inc. The remaining authors declare that the research was conducted in the absence of any commercial or financial relationships that could be construed as a potential conflict of interest.

Authors' contribution: All the authors contributed equally to prepare this article, read and approved the final manuscript.

\section{Acknowledgement:}

We acknowledge all our colleagues, Secretaries for their help during the preparation of the manuscript by providing all the relevant information. Thanks to Ms. Bethany Pond for her editorial assistant. Funds are from Nanoviricide, Inc. company and they are here-by acknowledged.

Fundings: Nanoviricde's, Inc own fund.

Ethical Statement: Not applicable 


\section{References:}

[1] Andersen, K.G., Rambaut, A., Lipkin, W.I. et al. The proximal origin of SARSCoV-2. Nat Med . 2020; https://doi.org/10.1038/s41591-020-0820-9.

[2] Singhal, T. A Review of Coronavirus Disease-2019 (COVID-19). The Indian Journal of Pediatrics. 2020; 87(4): 281-286. https://doi.org/10.1007/s12098-02003263-6.

[3] Chakraborty A and Diwan A et. al. Covid -19: Search for therapeutics. Integrative Molecular Medicine. 2020; 7: 1-8. Doi: 10.15761/IMM.1000407

[4] Ashok Chakraborty, Anil Diwan, Vijetha Chiniga, Preetam Holkar, and Vinod Arora. A short review on COVID-19: A great concern to public health. Trends in Res, 2020; 3: 1-2. Doi: 10.15761/TR.1000167

[5] Covid.cdc.gov/covid-data-tracker/; Updated: Sep 12, 2021.

[6] WHO Coronavirus Disease (COVID-19) Dashboard. Data last updated: 2021/10/10, https://covid19.who.int/.

[7] [Xie Y, Ogah CA, Jiang X, Li J, Shen J. Nucleoside inhibitors of hepatitis C virus NS5B polymerase: a systematic review. Curr Drug Targets 2016;17:1560-76.

10.2174/1389450117666151209123751 26648061].

[8] [COVID-19 Treatment 2020.

https://www.covid19treatmentguidelines.nih.gov/antiviraltherapy/remdesivi/ 
[9] Gordon CJ, Tchesnokov EP, Feng JY, Porter DP, Götte M. The antiviral compound remdesivir potently inhibits RNA-dependent RNA polymerase from Middle East respiratory syndrome coronavirus. J Biol Chem. 2020 295(15):4773-4779. doi: 10.1074/jbc.AC120.013056.

[10] Sheahan TP, Sims AC, Graham RL, Menachery VD, Gralinski LE, Case JB, et. al. Broad-spectrum antiviral GS-5734 inhibits both epidemic and zoonotic coronaviruses. Sci Transl Med. 2017 Jun 28;9(396):eaal3653. doi: 10.1126/ scitranslmed.aal3653.

[11] Wang M, Cao R, Zhang L, Yang X, Liu J, Xu M, et. al. Remdesivir and chloroquine effectively inhibit the recently emerged novel coronavirus $(2019-\mathrm{nCoV})$ in vitro. Cell Res. 2020 Mar;30(3):269-271.

doi: 10.1038/s41422-020-0282-0.

[12] de Wit E, Feldmann F, Cronin J, Jordan R, Okumura A, Thomas T, et. al. Prophylactic and therapeutic remdesivir (GS-5734) treatment in the rhesus macaque model of MERS-CoV infection. Proc Natl Acad Sci U S A. 2020; 117(12):6771-6776. doi: $10.1073 /$ pnas.1922083117.

[13] Lo MK, Feldmann F, Gary JM, Jordan R, Bannister R, Cronin J, et. al. Remdesivir (GS-5734) protects African green monkeys from Nipah virus challenge. Sci Transl Med. 2019; 11(494):eaau9242. doi: 10.1126/scitranslmed.aau9242.

[14] Warren TK, Jordan R, Lo MK, Ray AS, Mackman RL, Soloveva V, et. al. Therapeutic efficacy of the small molecule GS-5734 against Ebola virus in rhesus monkeys. Nature. 2016;531(7594):381-5. doi: 10.1038/nature17180. 
[15] Williamson BN, Feldmann F, Schwarz B, Meade-White K, Porter DP, Schulz J, et.al. Clinical benefit of remdesivir in rhesus macaques infected with SARS-CoV-2. Nature. 2020 Sep;585(7824):273-276. doi: 10.1038/s41586-020-2423-5].

[16] Remdesivir (RDV). 2020.

https://www.rxlist.com/consumer_remdesivir_rdv/drugs-condition.htm.;

[17] Adamsick ML, Gandhi RG, Bidell MR, Elshaboury RH, Bhattacharyya RP, Kim AY, et. al. Remdesivir in Patients with Acute or Chronic Kidney Disease and COVID19. J Am Soc Nephrol. 2020; 31 (7): 13841386. DOI: 10.1681/ASN.2020050589.

[18] Saleh J, Peyssonnaux C, Singh KK, Edeas M. Mitochondria and microbiota dysfunction in COVID-19 pathogenesis. Mitochondrion. 2020; 54:1-7. https://doi.org/10.1016/j.mito.2020.06.008.

[19] NanoViricides, Inc. The virus catchers. Nature BioPharma Dealmakers. 2016; June, B20.

[20] NanoViricides, Inc. NanoViricides is Developing Drugs Against SARS-CoV-2 with an Integrated Approach to Combat COVID-19, as Reported at The LD 500 Virtual Conference. Published: Sep 04, 2020.

https://www.biospace.com/article/releases/nanoviricides-is-developing-drugs-againstsars-cov-2-with-an-integrated-approach-to-combat-covid-19-as-reported-at-the-ld-500virtual-conference/. 


\section{Figures:}

Fig. 1A: A Novel Platform Technology: Nanoviricide is a Cell Mimic
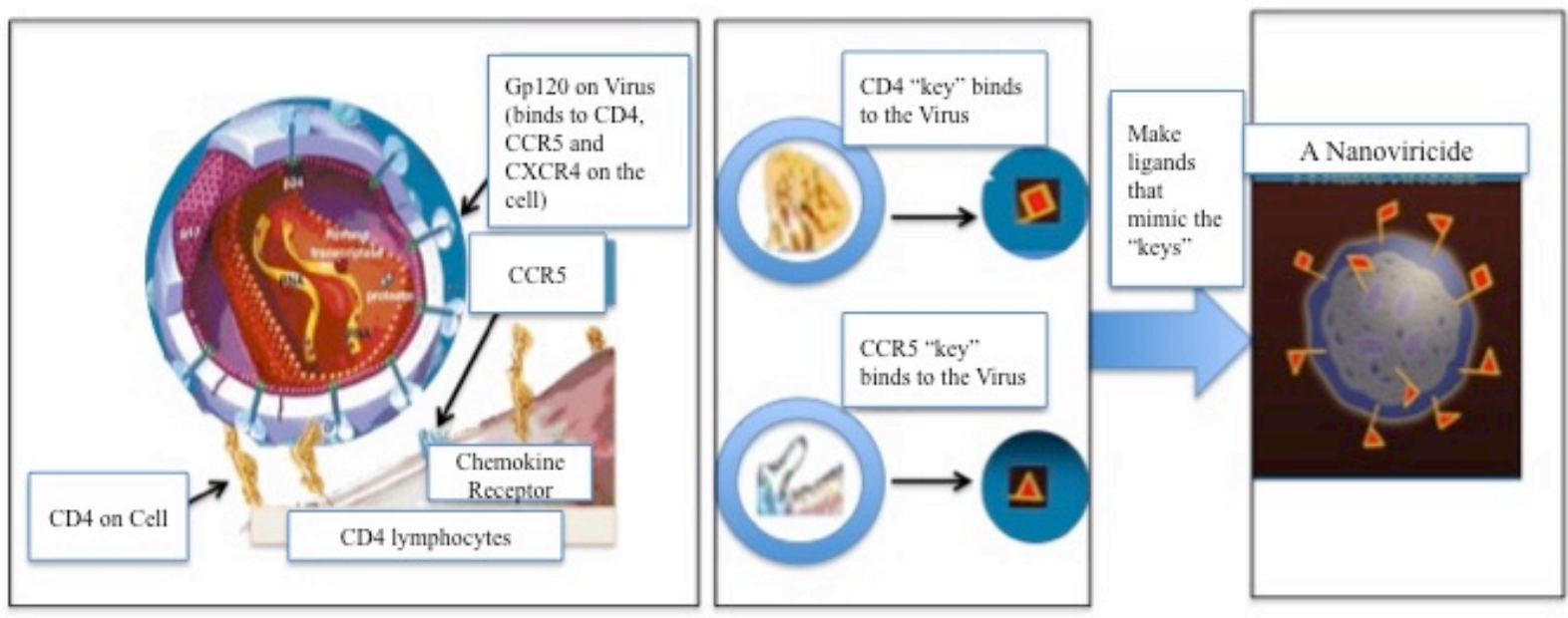

Fig. 1B: Mechanism of nanoviricde action:
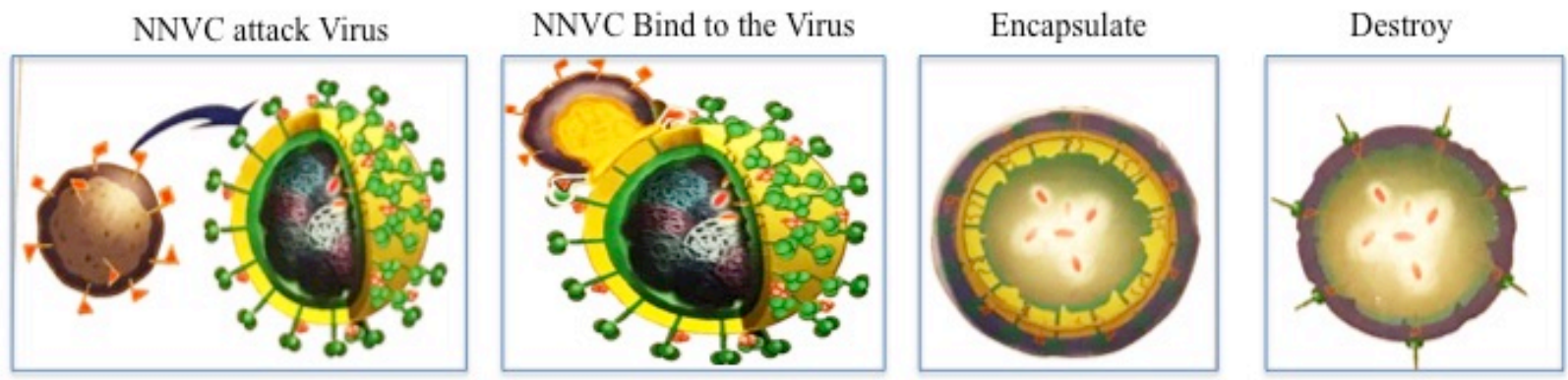

Fig. 1A: Novel Platform technology: Nanoviricide is a Cell Mimic: A Virus particle binding to a

\section{Cell via CD4 and a co-Receptor.}

A nanoviricide "looks like" a human cell to the virus. Nanoviricide is large enough for a virus particle to latch onto it, however, it is yet small enough to circulate readily in the body. Rather than a virus particle entering into a nanoviricide, a nanoviricide wraps around the virus particle and encapsulate it, by using the virus particle's very same ability to enter a cell. Viral resistance to the Nanoviricide drug is unlikely because even as the virus mutates, it still binds to the same cell surface receptor(s), in the same fashion.

Fig. 1B: A schematic presentation of nanoviricide action on virus particle. 


\section{Fig. 2: Standard Curve of RDV and GS-441524:}
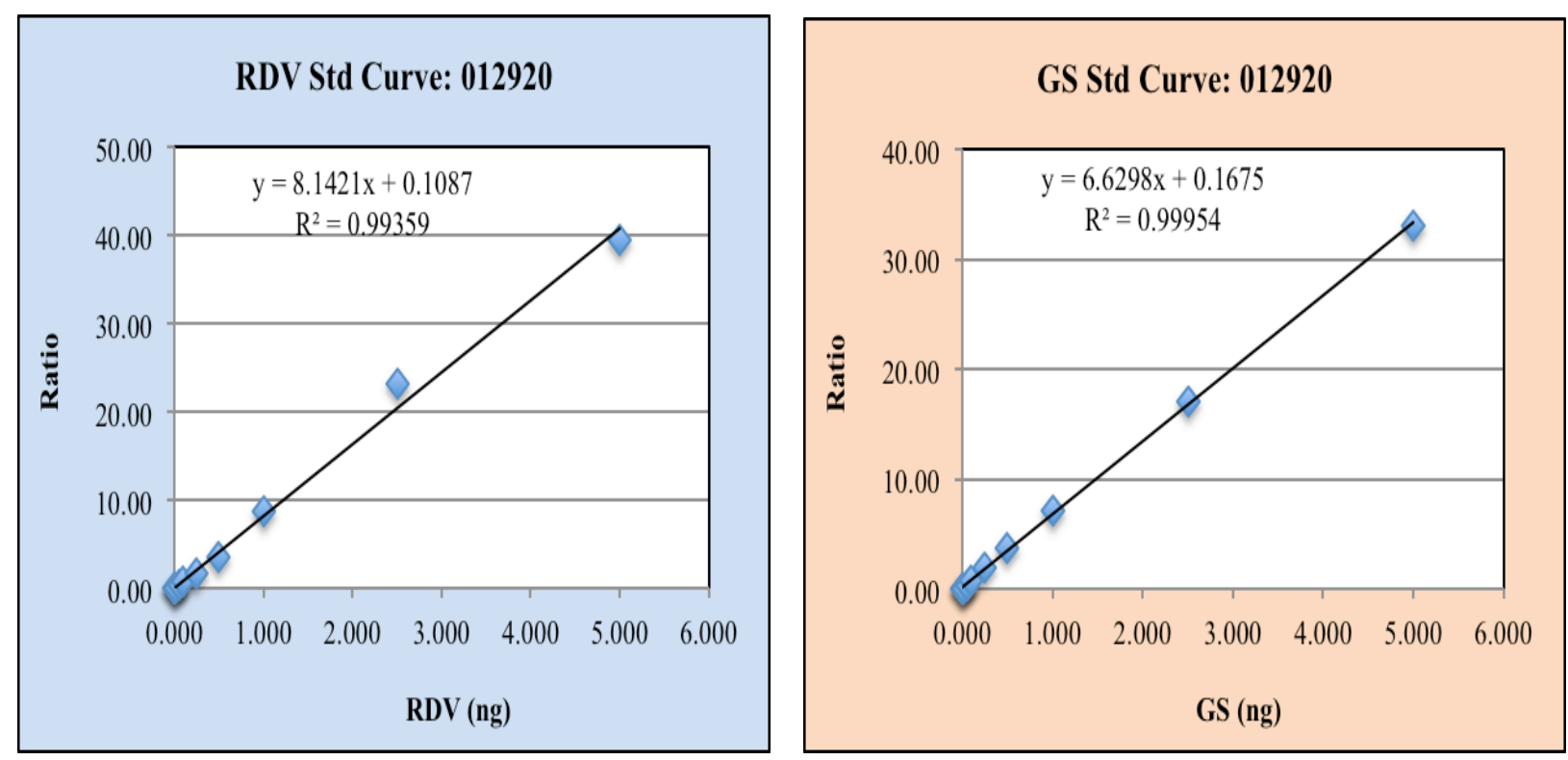

Fig. 2: Standard Curve of Remdesivir and GS-441524 were determined by using LC-MS, using different concentration of the standards solution in DMSO + $\mathrm{MeOH}$ (1:9) ranging from 0-5 ug/mL final concentrations. Plasma and/or PBS were used in the reaction mixture, as when needed. As an internal standard (ISTD) ${ }^{13} C_{6}-$ $R D V$ and ${ }^{13} C_{5^{-}} G S, 2.5 \mathrm{ug} / \mathrm{mL}$ each, were used, respectively for RDV and GS assay, and or in mixture. Final extraction of RDV and it's metabolite GS, were dome by using acetonitrile. 
Fig. 3: Stability of RDV in DMSO (NV1104-376B) incubated with RPL in vitro:
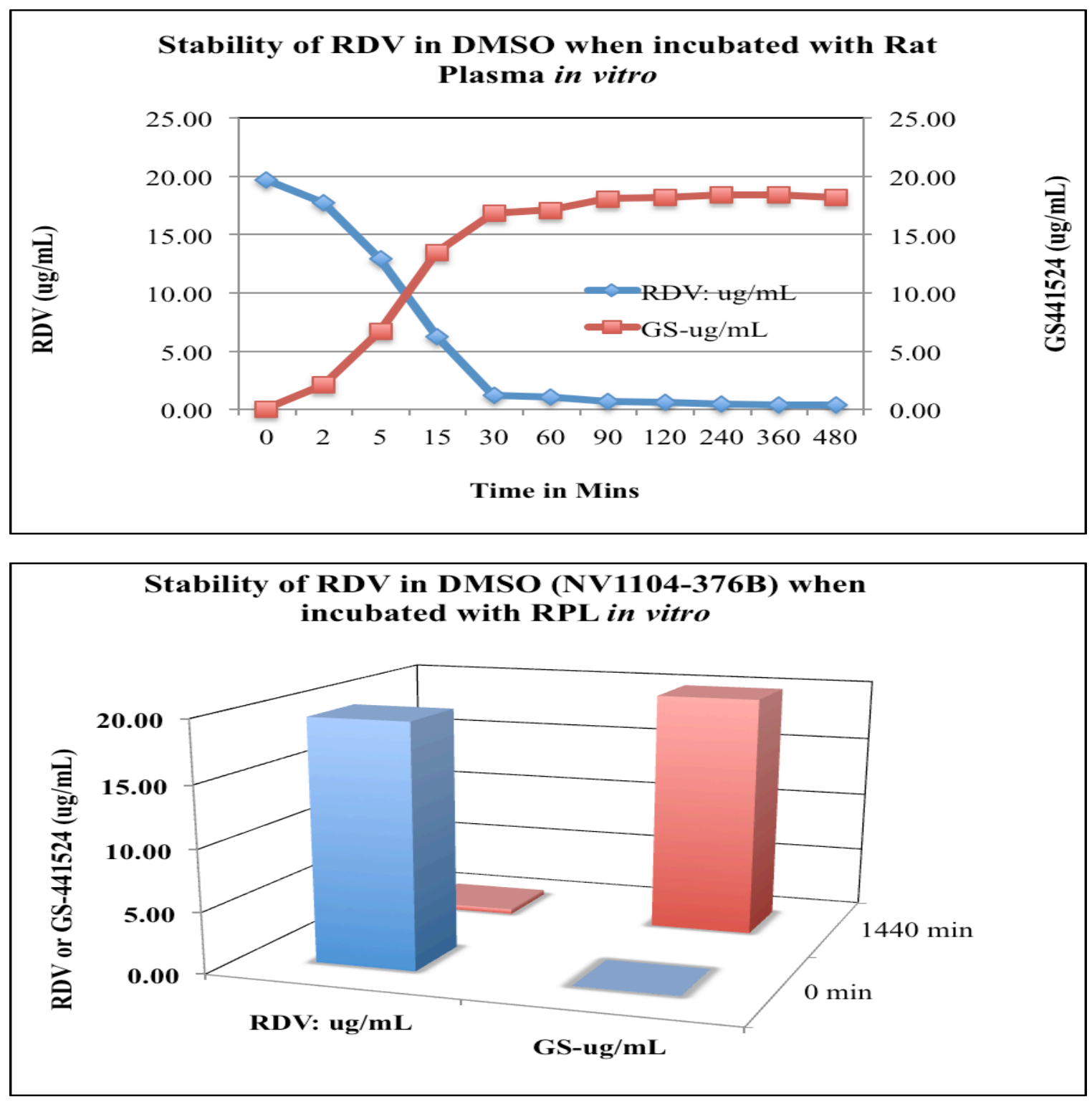

Fig. 3: Stability of RDV in DMSO (NV1104-376B) incubated with RPL in vitro: The sample, RDV (in DMSO), was tested for their stability in presence of Rat Plasma in vitro. Methodologies of incubation in reaction mixture, extractions, are same as we did for standard curve determinations of RDV/GS-441524. The results show that RDV alone has a very short life in presence of Plasma. GS-metabolite formations are representative of $R D V$ breakdown, and supportive to each other data. Each data points are the Mean $\pm S D$ of three experiments done in duplicate. 
Fig. 4: Stability of RDV encapsulated in polymer (NV1104-387B) and incubated with RPL in vitro :
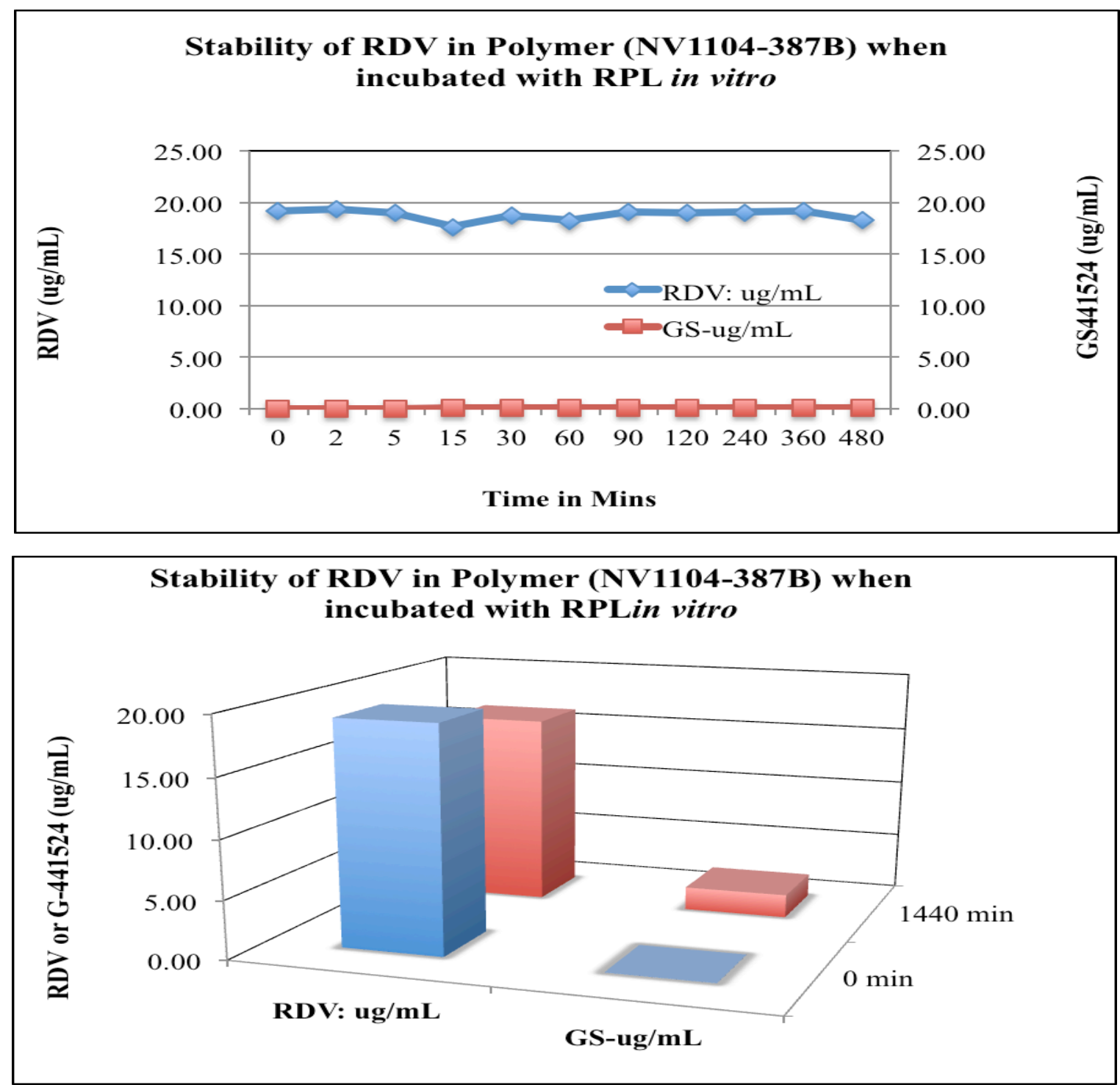

Fig. 4: Stability of RDV encapsulated in polymer (NV1104-387B) and incubated with RPL in vitro: The sample was tested for their stability in presence of Rat Plasma in vitro. Unlike of RDV in DMSO, we noticed here the protective capacity of polymer encapsulation of RDV from it's plasma-mediated breakdown. Each data points are the Mean $\pm S D$ of three experiments done in duplicate. 
Fig. 5: Stability of RDV in SBECD (NV1104-376A; Gilead) in RPL, in vitro
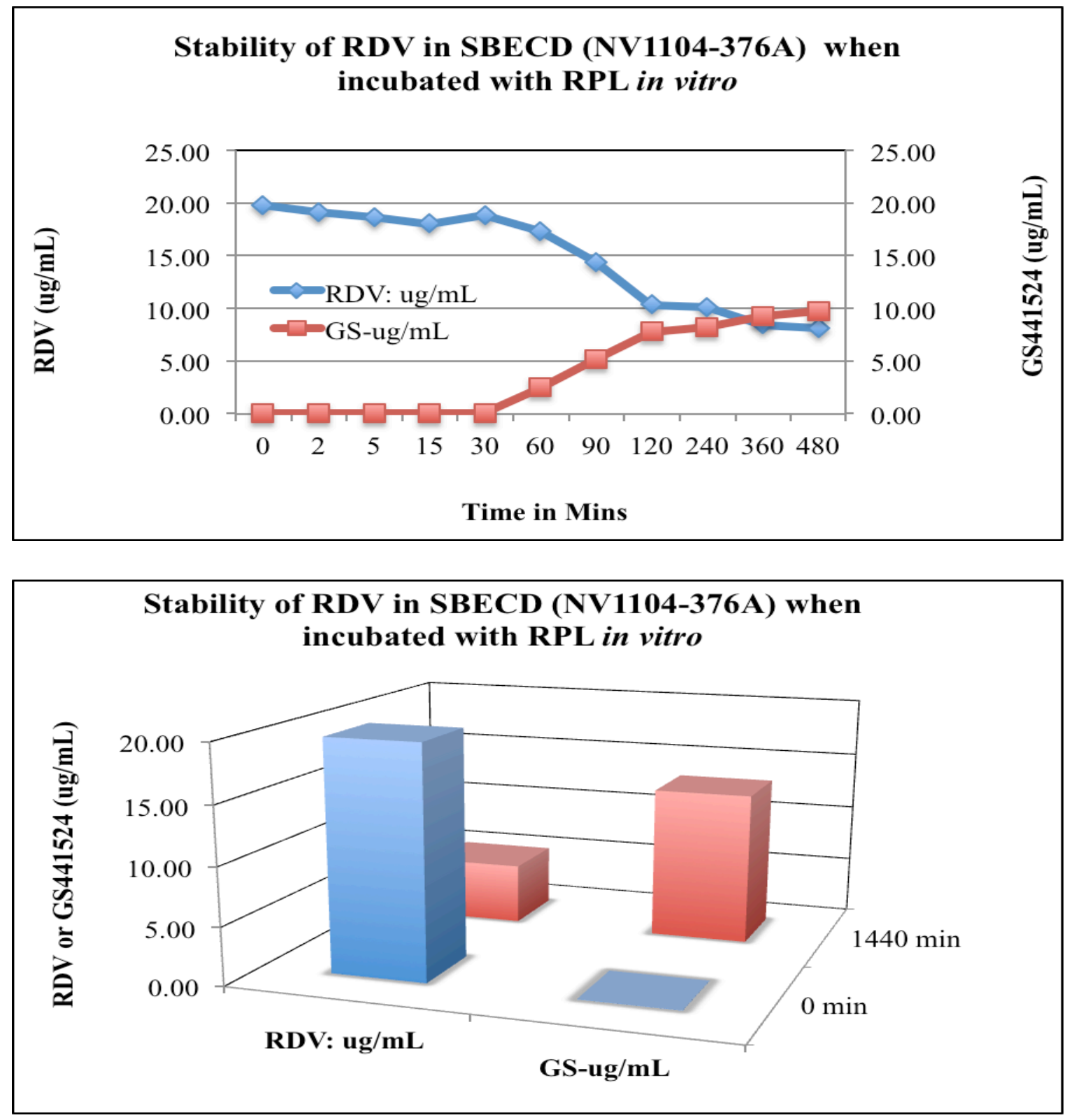

Fig. 5: Stability of RDV in SBECD (NV1104-376A; Gilead) in RPL, in vitro: The samples RDV in SBECD (Gilead) were tested for their stability in presence of Rat Plasma in vitro as described in Methodologies section. GS-441524, the RDV metabolite formations are representative of $R D V$ breakdown, and supportive to each 
other data. Each data points are the Mean $\pm S D$ of three experiments done in duplicate.

Fig. 6: Comparison of Stability of RDV in DMSO, in polymer 387 encapsulated, and in SBECD in presence of RPL, in vitro (Fig. 6):

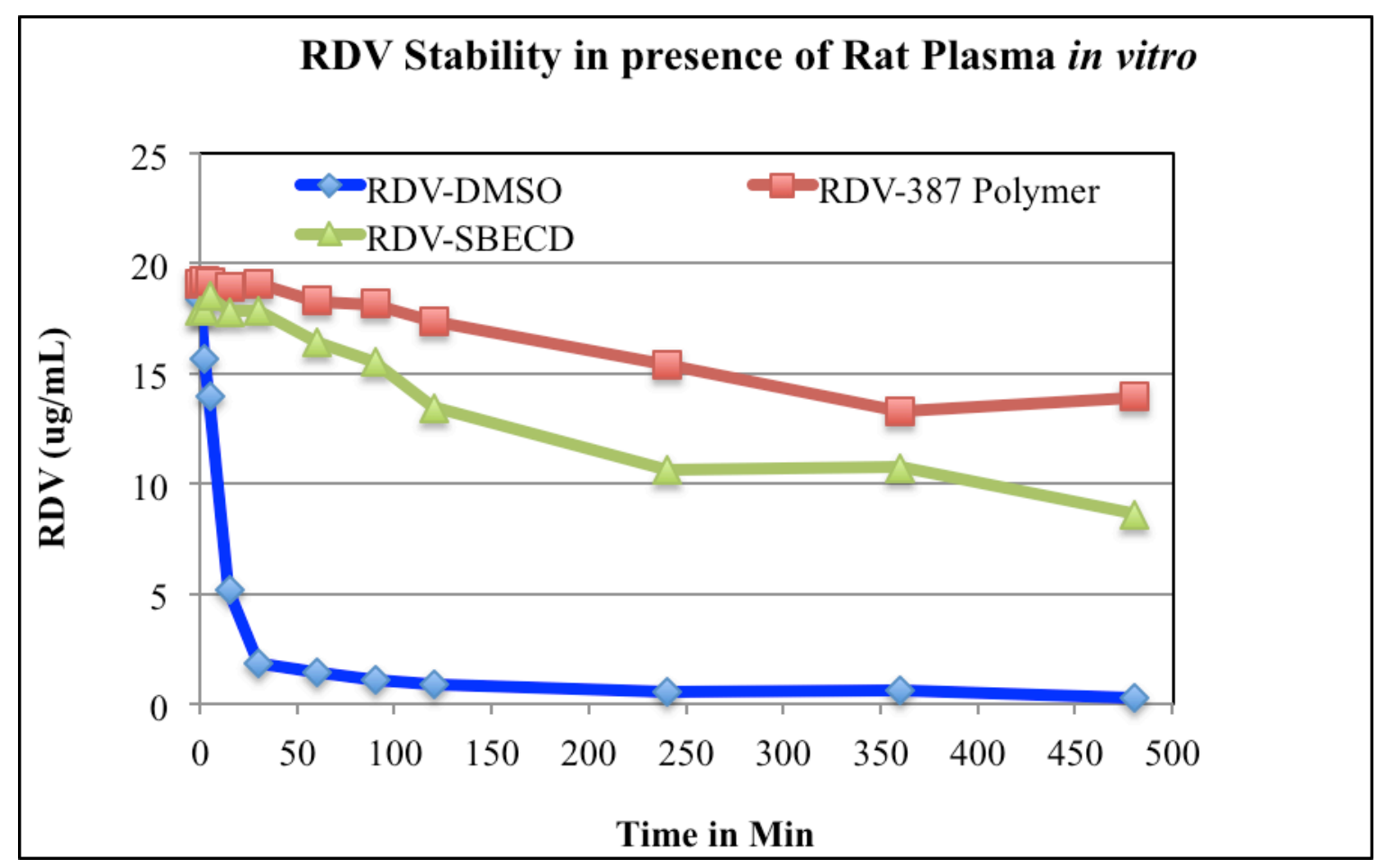



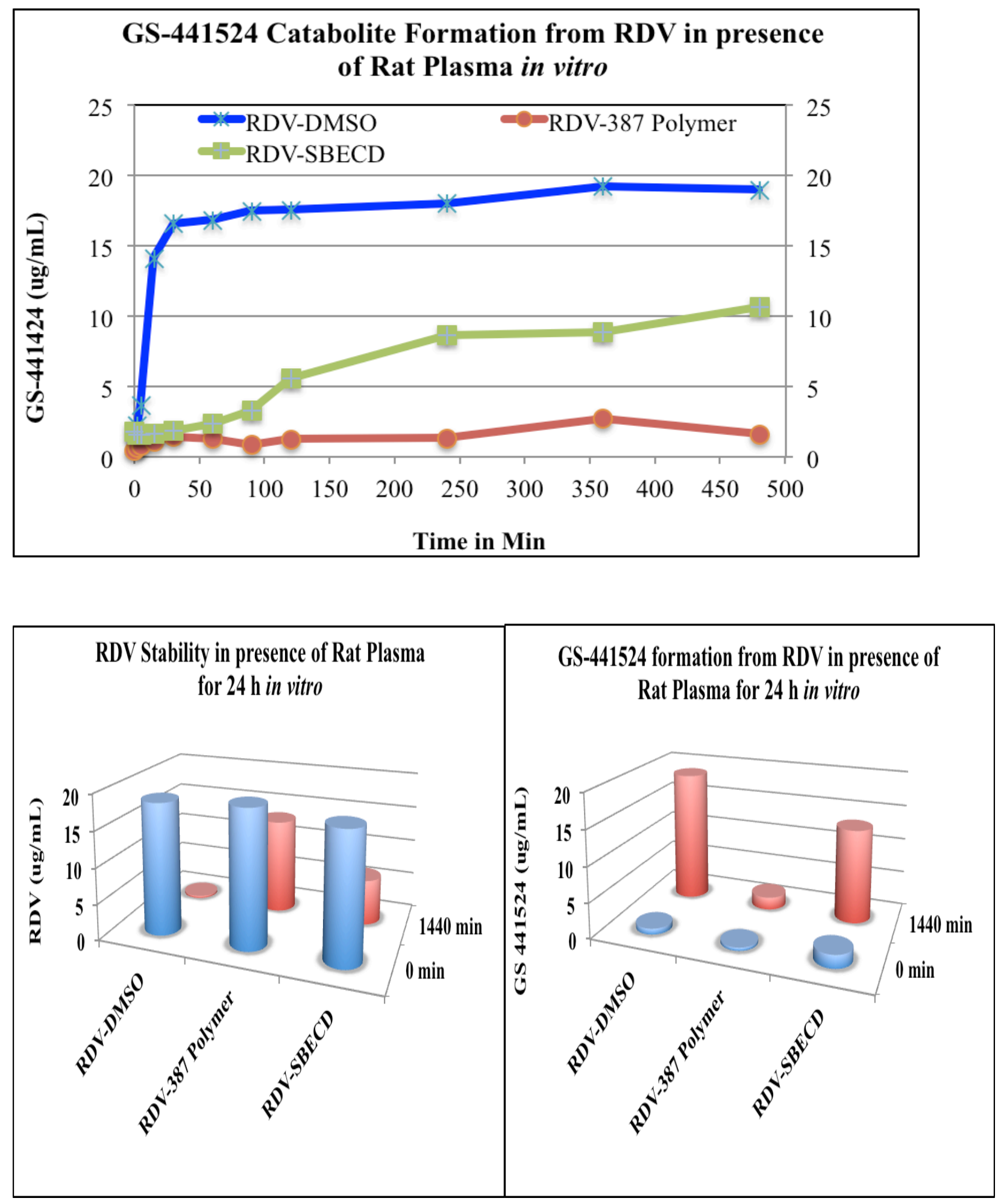

Fig. 6: Comparison of Stability of RDV in DMSO, in polymer 387 encapsulated, and in SBECD-In vitro in presence of Rat Plasma: Stability in RPL: The samples, 
$R D V$, RDV-encapsulated in MM6 Polymer, RDV in SBECD (Gilead) were tested for their stability in presence of Rat Plasma in vitro. Methodologies of incubation in reaction mixture, extractions, are same as we did for standard curve determinations of $R D V / G S$. The results show that RDV alone has a very short life in presence of Plasma, but encapsulation in NV-387 polymer make them very stable even after overnight incubation, even compared to Gilead RDV product. GS-441524 metabolite formations are representative of $R D V$ breakdown, and supportive to each other data. 